\title{
On the Theoretical Thinking of Overall Planning for the Public Goods Supply of China
}

\author{
Meiying Yang \\ School of Economics \& Management, Changchun University of Science \& Technology \\ Changchun 130022, China \\ $\&$ \\ Business School, Jilin University \\ Changchun 130012, China \\ E-mail: yangmy996@139.com
}

Received: July 3, $2011 \quad$ Accepted: July 28, $2011 \quad$ Published: October 1, 2011

doi:10.5539/ass.v7n10p63 URL: http://dx.doi.org/10.5539/ass.v7n10p63

Fund Item: The article is phase achievements of Jilin social science fund project "Exploration and Analysis on the Path of Public Goods Supply under Overall Planning in Jilin Province” (item number: 2011B397).

\begin{abstract}
The fundamental method of scientific outlook on development is to make overall plans and take all factors into consideration. To carry out the scientific outlook on development, build a well-off society in an all-around way, realize social harmony and guarantee benign and rapid development of social economy requires the government to make an overall plan as the subject and direct development of Chinese public goods supply in a scientific way. This article starts out from reality in China and makes a primary discussion on the issue of overall planning for the public goods supply of China.

Keywords: Significance of overall planning for the public goods supply of China, Target model, Realization approach

\section{Connotation and significance of overall planning for the public goods supply of China}

\subsection{Connotation of overall planning for the public goods supply of China}

Public goods refer to social products or services required to satisfy social public demands, guarantee sustainable and continuously development of human society and continue to realize social public interests in the process of highlighting social public value. Overall planning for the public goods supply of China means that the government plays the role of the subject in planning and guiding, takes into consideration the actual need of building a well-off society in an all-around way and realizing the magnificent strategic target of building socialist modernization, starts out from overall implementation of the scientific outlook on development, establishes socialist harmonious society and realizes benign and fast development of the economy. With a view to the objective reality of the preliminary stage of socialism and the current condition of social public goods supply, the government should follow internal requirement for development of Chinese public goods supply, make a unified plan and scientific guidance to public goods supply, continue to resolve contradictions of interests, adjust any imbalance and satisfy social public demands to the greatest extent so as to realize the developmental process of high quality, high efficiency and coordinated lasting of public goods supply.
\end{abstract}

\subsection{Significance of overall planning for the public goods supply of China}

Overall planning for the public goods supply of China is an important guarantee to deeply carry out the scientific outlook on development, promote benign and rapid development of economy, build a well-off society in an all-around way and realize the strategic target of social harmony and socialist modernization. Currently, China is at a critical stage to establish a socialist harmonious society, build a well-off society in an all-around way and make efforts for finally realizing the magnificent target of socialist modernization. Public demand is rapidly and 
comprehensively growing, the demand fields are continuously extended and expanded, and especially demand on the following public goods has become a general focus of the whole society: compulsory education, public medical care, poverty relief, social security, public security, environmental protection and social justice, etc. Public goods supply is closely related with current people's livelihood interests. Overall planning for the public goods supply of China is the specific application and vivid reflection of scientific outlook on development in the field of public goods supply and is also the application and specific reflection of the following principle in the field of public service: development by people, development for people, people sharing development achievement and human orientation. It can not only resolve current imbalance in economic and social development existing in China, polarization of rich and poor, great gap between their incomes, obvious distinctions between urban and rural areas, lagging of public security and environmental protection, and so on which are a series of problems to be urgently resolved, effectively defuse interests contradictions in social development and create favorable conditions for benign and rapid development of economy, but can also help to give full play to its functions of "safety valve" and "stabilizer", and offer important guarantee for ultimate realization of the strategic target of establishing a harmonious socialist society, a well-off society in an all-around way and socialist modernization.

\section{The target model for overall planning for the public goods supply of China}

Overall planning for the public goods supply of China has to gradually set up the target model of "government coordination, government guiding, development of plural supply subjects, sound system, perfect mechanism, harmonious matching of dynamic supply and demand and coordination of fairness and efficiency" according to basic requirements of carrying out the scientific outlook on development and setting up a harmonious socialist society.

\subsection{Government coordination}

The so-called government coordination means that the government plays the role of subject in making an overall plan, takes into consideration requirement for establishing the magnificent target of socialist modernization, starts out from carrying out the scientific outlook on development in an overall way, setting up a harmonious socialist society and realizing benign and rapid development of economy, gets established in realization of the maximization of social public interests with a view to the objective reality of the primary stage of socialist and the current condition and actual problems of social public goods supply, adapts to internal requirement of Chinese public goods supply development and makes an overall plan about supply of Chinese public goods.

\subsection{Government guiding and development of plural subjects}

The so-called government guiding and development of plural subjects means that overall planning for the public goods supply of China has to be based on establishment of a subject structure which is guided by the government with development of plural subjects. In such a structure, as the representative for social administrator and public interests, the government shoulders the obligations of furnishing public goods to the society, satisfying social public demands, adjusting people's interests, maintaining social and economic order, controlling normal operation of economy and realizing efficiency and fairness. This determines that the government has to take a leading role in supply of public goods. Insisting in the leading role of the government in supply does not mean negating and excluding existence and development of plural supply subjects. On the contrary, existence and development of plural supply subjects should be regarded as the premise and condition. Only if private sections, social organizations and other non-governmental sections extensively enter the field of public goods supply and constitute together with the government the subject of public goods supply, which means pluralization of supply subjects, can the leading position of the government be established and highlighted. Thus, in order to realize the position and function of the government in public goods supply, we have to develop positively plural supply subjects, advocate and encourage private sections, social organizations and other non-governmental sections to enter the field of public goods supply, realize plural subjects who should perform their own functions, supplement and promote each other and develop together.

\subsection{Sound system and perfect mechanism}

The so-called sound system means that overall planning of social public goods supply should offer indispensable guarantee for overall planning for the public goods supply of China by means of sound system and perfect legal rules and regulations. The so-called perfect mechanism means that overall planning for the public goods supply of China should set up a supply mechanism with dynamic coordination, complementary integration and perfect functions. There exist objectively three kinds of allocation mechanisms in public goods supply, namely, "administrative mechanism" of the government, "efficiency mechanism" of the market and "voluntary mechanism" of social organizations. All these three kind of mechanisms have their own functioning scope and 
boundary and none is omnipotent, since each of them may have the problem of malfunction. In one word, malfunction of the government mechanism is intensively manifested as low efficiency of supply of public goods; malfunction of the market is intensively manifested as non allocation of public resources, insufficient allocation or irrational allocation which means impossibility to realize fairness; malfunction of social organizations is intensively manifested as limited allocation scope, field and motive, which means they can not resolve problems fundamentally.

\subsection{Harmonious matching of dynamic supply and demand and coordination of fairness and efficiency}

The so-called harmonious matching of dynamic supply and demand means that in the process of overall planning for the public goods supply of China, we not only have to pay attention to the current development, but should be established in the future and we should not only pay attention to realizing coordinated condition of supply and demand of public goods from multiple perspectives, multiple dimensions and multiple levels in terms of space, but should also pay attention to harmonious matching of supply and demand in terms of time.

The so-called coordination of fairness and efficiency means that, in the process of overall planning for the public goods supply of China, we should realize dynamic and optimal combination of the targets of fairness and efficiency and realize interactive growth in development and internal unification of the two according to specific conditions at different stages of the social development. As a matter of fact, it emphasizes equal importance of fairness and efficiency. Here the social fairness not only includes "fairness of opportunities and fairness of rules", but also refers to political fairness, education fairness, judicial fairness, medical care fairness, environmental fairness and social security fairness, etc, which are concerned with overall development and basic rights of human kind. Here, the efficiency not only refers to increase of economic benefits, but also refer to continuous increase of social benefits so as to realize balanced development of economic benefits and social benefits. We should not only pursue macro benefits, but also guarantee micro benefits and realize unification of macro benefits and micro benefits. We should not only take into consideration static benefits, but should more take into consideration dynamic benefits and emphasize dialectical unification of immediate benefits and long term benefits. We should not only emphasize total benefits of national economy, but should also emphasize local benefits of a region and a department and advocate overall benefits of the country and a region, urban and rural areas.

\section{Approaches to realize the target model of overall planning for the public goods supply of China}

\subsection{To be led by the scientific outlook on development, speed up development and to lay foundation for} realization of "coordination model"

Firstly, to be led by the scientific outlook on development and offer theoretical guidance for realization of "coordination model". Overall planning for the public goods supply of China is an organic component in development of Chinese economy and society. Only if we regard the scientific outlook on development as the leading direction and speed up development, can we offer indispensable theoretical guidance for the ultimate realization of the target model of "government coordination, government guiding, development of plural supply subjects, sound system, perfect mechanism, harmonious matching of dynamic supply and demand and coordination of fairness and efficiency".

Secondly, to speed up development of market economy and to lay economic foundation for realization of "coordination model". Realization of the "coordination model" and development of the market economy is closely related. The more the market economy is developed, the more material wealth is created, the more the financial amount for disposal by the government, and the more solid is the material foundation of the government overall planning for the public goods supply of China. In the meanwhile, development of the market economy and sound and perfect market system and mechanism will also help to facilitate sound system of public goods supply and perfect mechanism and better realize unification of fairness and efficiency.

Thirdly, to speed up construction of a civil society and to build a social environment for realization of "coordination model". A sound society should be one in which the market, society and the country each perform its own function and the three maintain a relationship of coordinating, balancing and supplementing. Cultivation and development of the civil society is the social foundation for "coordination model" to be realized. At present, China is still a typical civil society that is led by the government and non-governmental organization has still not been generated since it is not standard and its development is imbalanced, which is likely to give rise to a weak and even lost social environment required by "coordinating model", In order to realize "coordination model", it is necessary to create a required social environment, which has to be based on leading of the scientific outlook on development and on speeding up construction of a civil society. 


\subsection{To improve and enhance the structure of supply subjects and to offer plural subjects for realization of "coordination mode"}

In order to realize overall planning for the public goods supply, we have to give full play to the leading role of the government. The government should not only make up for malfunction of the market, assume national defense and administration and create, cultivate and standardize market which the market is unable to allocate, but also should take into consideration of the needs of the overall interests, long term interests and fundamental interests of the country and supply public goods which other subjects are unable to supply or supply effectively but which are related with the overall situation of economic and social development. The government should not only perform the function of supplying public goods, but should also burden the obligation of private sections and non-governmental organizations to guide and standardize healthy development of other subjects, give full play to the function of public goods supply subjects of the third sections, international organizations and private sections, realize plural subjects each performing their own functions, supplementing each other, promoting each other and developing together. In order to give full play to this leading role, it is not only required to set up scientific and highly effective track and supervision mechanism for demand on public goods so as to enable the government to know about and grasp content, level, scale and distribution, etc. of demand on social public goods, but also required to facilitate reform on administrative system of the government, set up and improve decision making mechanism for supply of public goods by the government so as to improve decision making level of the government and offer correct decision making guarantee for the government to direct public goods supply. Also, it is need to improve relevant systems which have the function of "plural subjects" and offer guarantee for development of supply subjects of the third section and enterprises from the perspective of system.

Secondly, it is necessary to cultivate social organizations and give full play to their important role in public goods supply. According to experience of international public goods supply, social organization is an indispensable supply subject in the field of public goods and plays a relatively important role in public goods supply. Social organization not only helps to make up for malfunction of the government but can also make up for disadvantages of the market in terms of supplying public goods, since it can effectively make up for public goods which the government and the market are unable to supply or are in shortage of. Ever since the reform and opening up, Chinese social organizations have been emerging gradually and have been rapidly developed, but the number of social organizations is small and the forms are tedious, with undefined legal status. Their functions are limited and not standard, which obstructs their functions in supply of public goods. In order to realize overall planning for the public goods supply of China, we are required to cultivate social organizations and five full play to their important role in supply of public goods. Thirdly, it is necessary to expand supply scope of enterprise products and give full play to their positive role in public goods supply. Enterprises are also one of the subjects for supply of public goods, which play an active role in supply of public goods. In supply of public goods, enterprises are able to supply exclusive standard public goods. Compared with supply of public goods by the government and social organization, supply of public goods by enterprises is neither aimed to realize social fairness nor aimed at "concern" for public demand of particular public members in the society, but is aimed at making profits so as to offer sufficient motive for supply of public goods by enterprises, which exactly makes up for disadvantages of social organizations in their motive for supplying public goods and makes up for the deficiency in being unable to satisfy social public demands in a sustainable, stable and sufficient way.

\subsection{To deepen reform, improve mechanism and create institutional mechanism conditions required for realization of "coordination mode"}

Firstly, it is necessary to deepen political system restructuring, change government functions and ensure that the "coordination" of government is in place. Currently, to transfer the government function has to be established in actual national situation of China, be directed by adaptation to Chinese public demand development, and realize the fundamental transfer of the government functions from "management" to "service", from "infinite" to "limited" and from "centralization of state power" to "decentralization of state power". In order to realize this fundamental change, we have to vigorously push forward political system restructuring, change government supply principle and supply behavior mode and realize rational separation of powers between the government and local government and create necessary conditions for the government to change their functions. In the meanwhile, overall planning for the public goods supply also needs to deepen restructuring of economic system, push forward with emphasis and focus reform of financial system, reform of distribution system, reform of social security system, reform of sanitary and medical services system and system of education system and build necessary system conditions for realization of "coordination mode". At the same time, it is required to set up, improve and carry out a series of legal rules that are related with social public goods supply, formulate legal system required for guaranteeing overall planning for the public goods supply of China and lay necessary legal 
system foundation for overall planning for the public goods supply of China. Besides, it is necessary to accelerate innovation, realize unification of fairness and efficiency and create necessary mechanism conditions for realization of "coordination mode". In order to realize unification of fairness and efficiency, it is a must to accelerate innovation, enable "administrative mechanism" of the government, "efficiency mechanism" of the market and "voluntary mechanism of social organizations" to each play their advantages and make the best of these mechanisms. Specifically speaking, from the perspective of "administrative mechanism", it is necessary to strengthen system innovation and strengthen efficiency of public goods supply; it is necessary to innovate government public service system, enlarge study on survey of public demand and set up scientific and rational financial expenditure decision making mechanism; it is necessary to set up supervision mechanism to restrain and punish corruption; it is necessary to push forward democratic construction and prevent occurrence of all sorts of malpractice and dereliction of duty. From the perspective of "efficiency mechanism" of the market, it is necessary to push forward system reform and break through local blockage and section monopoly; it is necessary to explore and innovate forms and specific approaches for enterprises to participate in public goods supply; it is necessary to formulate laws to support and standardize enterprises participating in public goods supply. From the perspective of "voluntary mechanism", it is necessary to carry out corresponding policies and vigorously encourage development of social voluntary organizations; it is necessary to explore different types of realization forms for "voluntary mechanism"; it is necessary to cultivate vigorously social charitable ideas and encourage development of multiple forms of private donation to the society; it is necessary to set up all sorts of social charity organizations and improve charity organization construction.

\section{References}

(2006). Decisions by the Central Committee of the CPC on Some Major Issues in Building a Harmonious Socialist Society. Beijing: people's Publishing House, 5.

Hu, Jintao. (2007). To Hold High the Great Socialism Flag with Chinese Characteristics and to Struggle for New Victory in Building a Well-off Society in an All-around Way. Beijing: People's Publishing House, 15.

Pu, Xingzu. (2005). Political System of People's Republic of China. Shanghai: Shanghai People's Publishing House, 233.

Song, Min. (2007). Effects and Enlightenment of Reform in Public Service Marketization in Western Countries. Economic Review, (4).

Yang, Meiying. (2008). Study on Overall Planning for the Public Goods Supply of China. Changchun: Northeast Normal University. 